\title{
Optimization of Emulsion Liquid Membrane for Lead Separation from Aqueous Solutions
}

\author{
Elsayed Fouad \\ Chemical and Materials Engineering \\ Department \\ Northern Border University \\ Arar, Saudi Arabia \\ sayedfou700@gmail.com
}

\author{
Farooq Ahmad \\ Chemical and Materials Engineering \\ Department \\ Northern Border University \\ Arar, Saudi Arabia \\ farooq chem@yahoo.com
}

\author{
Khaled Abdelrahman \\ Chemical and Materials Engineering \\ Department \\ Northern Border University \\ Arar, Saudi Arabia \\ km_abdelrahman@yahoo.com
}

\begin{abstract}
This study focuses on evaluating the process parameters and their effects on extraction of lead as well as emulsion breaking. The Signal / Noise ratios have been used to study the performance characteristics. Six parameters affecting extraction by emulsion liquid membrane, namely, TOPO, Span80, and internal phase concentration, feed/emulsion ratio, agitation time and feed $\mathrm{pH}$ have been optimized with considerations to lead extraction and emulsion breaking. The standardized effects of the independent variables and their interactions were tested by the analysis of variance (ANOVA) with $95 \%$ confidence limits $(\alpha=0.05)$ and Pareto chart. The use of the optimal values of these parameters has been proved useful in maximizing the extraction efficiency and minimizing the emulsion breakage. TOPO concentration of 0.1498 M, Span 80 concentration of $3.007 \mathrm{v} \%$, Internal phase concentration of 0.183 $\mathrm{M}$, Feed/emulsion volume ratio of 1.407 , agitation time of 30 minutes, and feed $\mathrm{pH}$ of 5 are determined as the optimum parameters.
\end{abstract}

Keywords-lead; optimization; taguchi method; emulsion liquid membrane

\section{INTRODUCTION}

Lead contamination in an environment is a very important problem worldwide due to its highly toxic and nonbiodegradable nature[1]. The industrialized activities using lead such as batteries, photographic materials, pigments, fuels and explosives have contaminated the environment. Various destructive effects have been found as a result of heavy metal pollution. Therefore, a limit of $0.01 \mathrm{ppm}$ for $\mathrm{Pb}$ in the surface water was recognized by WHO and USEPA [1]. There are several methods for treating $\mathrm{Pb}$ discharges such as smelting [2], adsorption [3], ion exchange [4], and liquid-liquid extraction [5]. Recently, liquid membranes [LM] have great attention to extract lead ions from wastewater streams [6-9]. Emulsion liquid membrane (ELM), combines an instantaneous extraction and stripping of the metal ion, is one of such methods. ELM consists of an internal aqueous phase captured by a membrane phase. The membrane phase consists of the extractant dissolved in an organic diluent together with a surfactant to obtain stable emulsion droplets. So, ELM process involves two steps (extraction and stripping) in one. The metal ions existing in waste solution form a complex with the extractant at the boundary of the emulsion globule and the aqueous feed phase.
The complex formed is then transported through the organic phase to the organic - stripping boundary from where it is stripped into the bulk of the internal aqueous phase $[10,11]$.

ELM is an effective technique and used for zinc removal. Commercialization for the removal of other heavy metals is limited due to emulsion breaking. The phenomenon of emulsion breaking has been attributed to the swelling of emulsion, i.e. water transport through the membrane causing in a decrease in the membrane / internal phase volume ratio. An increase in the internal phase volume will affect the dispersed droplets size distribution. Moreover, the interfacial film of the surfactant molecules will expand over a higher number of water droplets causing a decrease in density. The interfacial film will be no longer resistant against collisions, and hence, increasing coalescence rate [1]. Taguchi technique is a unique and powerful optimization tool that allows optimization with minimum number of experiments. This method can usefully optimize the emulsion liquid membrane [13-16]. The potential of this technique has not been utilized for the breaking of emulsion. In this paper Taguchi method has been used to explore the potential of this technique for the optimization of breaking of emulsion. Several other parameters affecting extraction of lead and emulsion breaking have been studied. These parameters include extractant and surfactant concentrations, stirring time, external phase acidity, internal phase concentration, and volume ratio of external phase to membrane phase.

\section{EXPERIMENTAL}

\section{A. Chemicals}

Tri-octyl phosphine oxide (TOPO) was used as a diluent. Sorbitan monooleate (Span 80) was used as a surfactant. Standard solution of $1000 \mathrm{ppm}$ of $\mathrm{Pb}++$ stock was prepared by the dissolution of the proper amount of lead (II) chloride, Sigma into acidified double distilled water. External aqueous phase was prepared by diluting the required volume of $1000 \mathrm{ppm}$ solution to the desired concentration.

\section{B. Emulsion Preparation}

According to the experimental runs in Table I, the organic solution was prepared in kerosene as a solvent by mixing with 
the right amounts of Span 80 and TOPO. The stripping aqueous solution of sulfuric acid as an internal phase was added to the organic solution under stirring at $10000 \mathrm{rpm}$ using an ultraturax T25 homogenizer for $10 \mathrm{~min}$, to produce the emulsion. The volume ratio of the internal phase to the membrane phase is 1 .

\section{Extraction procedure by ELM}

The emulsion phase was spread into the external lean solution containing $300 \mathrm{ppm}$ of $\mathrm{Pb}^{++}$ions, and the solution was agitated at $400 \mathrm{rpm}$ for an extraction time ranged from 1-30 min. The $\mathrm{Pb}^{++}$-TOPO complex diffuses through the membrane to the interface of the internal phase droplets. Thus, the reaction of back-extraction occurs, where the $\mathrm{Pb}^{++}$is preconcentrated in the internal phase and the extractant is regenerated. All extraction experiments were carried out in a batch system at room temperature of $25 \pm 1^{\circ} \mathrm{C}$. Aliquots of $10 \mathrm{ml}$ of raffinate aqueous solutions are taken for analysis. ICP (Perkin Elmer, Optima 7000 DV) is used for the analysis of $\mathrm{Pb}^{++}$ions. Equation (1) is used for the calculation of Extraction efficiency (E\%):

$$
E \%=\left[\left(C_{o}-C_{e}\right) / C_{o}\right] \times 100
$$

where $\mathrm{C}_{0}$ : initial concentration of $\mathrm{Pb}^{++}$in feed phase and $\mathrm{C}_{\mathrm{e}}$ : concentration of $\mathrm{Pb}^{++}$in the lean solutions. The volume of an emulsion was also measured after the extraction experiment to calculate emulsion breakage $(\mathrm{B} \%)$. The conductivity of the feed phase was estimated by a conductivity meter prior and after experiments. Emulsion breakage (B \%) was calculated by (2).

$$
B \%=\left[\left(V_{e} \times C_{e}\right) /\left(V_{i} \times C_{i}\right)\right] \times 100
$$

where $\mathrm{V}_{\mathrm{e}}$ and $\mathrm{C}_{\mathrm{e}}$ are the volume and concentration (in terms of conductivity) of the feed aqueous phase at the end each run. $V_{i}$ and $C_{i}$ are the initial volume and concentration of the external aqueous phase.

\section{Design of Experiments Using Taguchi Method}

The main objective of experimental design was to quantify the influence of the experimental aspects on extraction efficiency of lead, E\% and emulsion breaking, B \% using Taguchi Method. In Taguchi method an orthogonal array for the design of experiments was used. In this study, six controllable factors were examined: concentration of TOPO and Span 80 in the organic phase, concentration of sulfuric acid in the internal phase, feed / emulsion volume ratio, agitating time, and feed phase $\mathrm{pH}$. L25 orthogonal array was generated for five levels of each controllable factor (Table I). Only 25 tests, were conducted, rather than 7776 (i.e. 65) experimental runs, signifying a great saving in cost and time. In the Taguchi method, signal to noise $(\mathrm{S} / \mathrm{N})$ ratio signifies quality features for the experimental data. $\mathrm{S} / \mathrm{N}$ ratios were characterized into larger-the-better, nominal-the-best, and smaller the better. In the case of extraction efficiency ( $\mathrm{E} \%$ ), quality characteristic was selected as the larger the better. For emulsion breakage (B $\%)$, smaller the better quality characteristic was selected. The $\mathrm{S} / \mathrm{N}$ ratio is given for larger the better quality characteristic by (3) and smaller the better quality characteristic by (4) [13].

$$
\begin{aligned}
& S / N=-10 \log \frac{\sum_{i=1}^{n} \frac{1}{y_{i}^{2}}}{n} \\
& S / N=10 \log \frac{1}{\frac{1}{n} \sum_{i=1}^{n} y_{i}^{2}}
\end{aligned}
$$

where $n$ : number of trials under the identical experimental conditions, and $\mathrm{y}_{\mathrm{i}}$ : result of each repetitive measurement. From $\mathrm{S} / \mathrm{N}$ ratio, the influence of the effective factors on process results can be seen and the optimum conditions of process factors can be determined. The statistical analysis of the results is applied using Minitab 17 software. ANOVA is used to attain the contribution $\%$ of each factor.

\section{RESULTS AND DISCUSSION}

\section{A. Statistical Analysis}

Table I mimics the results of the 25 runs. The $\mathrm{S} / \mathrm{N}$ ratios were calculated by (3) and (4). The results showed that the E\% of $\mathrm{Pb}$ varied from 15 to $96.67 \%$ and $\mathrm{S} / \mathrm{N}$ ratios ranged from 23.5218 to $39.7-058$, dependent on the combination of the controllable factors. Figure 1 presents the $\mathrm{S} / \mathrm{N}$ ratio for each level of every controllable variable for Extraction efficiency. By inspection of Figure 1, TOPO concentration has the largest variance of $\mathrm{S} / \mathrm{N}$ ratios, whereas feed phase $\mathrm{pH}$ has the smallest ones. Therefore, TOPO concentration is the greatest significant controllable variable, while the non-significant factor is feed phase $\mathrm{pH}$. Further quantification of the significance of each controllable variable can be implies by the range of the $\mathrm{S} / \mathrm{N}$ ratio $\left(\mathrm{S} / \mathrm{N}_{\max }-\mathrm{S} / \mathrm{N}_{\min }\right)$ given in Table II. A factor with a large range indicates that this factor is more significant and must be employed first. The range in descendent order was TOPO $>$ Int. phase $>$ feed/emulsion ratio $>$ Span $80>$ Stirring time $>$ Ext. $\mathrm{pH}$.

For the second response B\% (Figure 2), results shows that the $\mathrm{B} \%$ varies from 4 to $72 \%$ and that the $\mathrm{S} / \mathrm{N}$ ratios vary from -37.1466 to -12.0412 . Because the smaller-the-better characteristic, the highest $\mathrm{S} / \mathrm{N}$ ratio is required to get the smallest breaking of emulsion (B \%) (Table III). In the case of internal phase concentration when the lowest concentration $(0.1 \mathrm{M})$ is applied, the emulsion breaking can be diminished. High levels of Span 80 concentration reduce the surface tension and then reduce the emulsion breaking to certain levels. The minimum emulsion breaking will be achieved at the lowest levels of TOPO and internal phase concentrations combined with the highest level of Span 80 concentration and moderate levels of external phase $\mathrm{pH}$ and external/emulsion ratio. So, the optimum conditions for the maximum extraction efficiency and minimum emulsion breaking can be established at conditions tabulated in Tables II and III.

\section{B. Pareto Charts}

The standardized effects of the distinct variables and their mutual interactive effects on the two responses are displayed in a Pareto charts (Figures 3 and 4). Figures 4 and 5 show the Pareto charts of standardized factor effects from which the size 
and significance of each effect can be predicted. The vertical line showed on the graph with $95 \%$ confidence limits $(\alpha=$ 0.05 ) allows us to find out the most significant effects, such that some effect that extends past this vertical line is important [16]. The length of each block in the graph shows the standardized effect of that variable on the response [17, 18]. From this Figure, it can be found that TOPO concentration is the most important parameter for lead extraction followed by
Span 80 and internal phase concentration. Also the interaction of Span 80 concentration and internal phase concentration plays an important role in emulsion liquid membrane system. Increasing Span 80 and internal phase concentration result in a more stable emulsion which improves the extraction \% of lead. Feed phase $\mathrm{pH}$ shows a least role in the recovery of lead by ELM.

TABLE I. EXPERIMENTAL DESIGN ORTHOGONAL ARRAY, RESULTS AND THEIR CORRESPONDING S/N RATIOS

\begin{tabular}{|c|c|c|c|c|c|c|c|c|c|c|}
\hline \multirow[b]{2}{*}{ Run } & \multicolumn{6}{|c|}{ Input parameters levels } & \multicolumn{2}{|c|}{ Observed values } & \multicolumn{2}{|c|}{$\mathrm{S} / \mathrm{N}$ ratio } \\
\hline & TOPO, M & $\begin{array}{c}\text { Span80, } \\
\text { v\% }\end{array}$ & $\begin{array}{c}\text { Int. phase, } \\
\text { M }\end{array}$ & $\begin{array}{c}\text { Ext/Emulsion } \\
\text { Ratio }\end{array}$ & $\begin{array}{l}\text { Stirring } \\
\text { time, min. }\end{array}$ & $\begin{array}{c}\text { Feed } \\
\text { pH }\end{array}$ & $\mathbf{E} \%$ & B\% & E\% & B\% \\
\hline 1 & 0.05 & 3 & 0.1 & 1 & 1 & 0.5 & 30.00 & 30.00 & 29.5424 & -29.5424 \\
\hline 2 & 0.05 & 5 & 0.3 & 5 & 5 & 1.0 & 50.00 & 26.00 & 33.9794 & -28.2995 \\
\hline 3 & 0.05 & 7 & 0.5 & 10 & 10 & 2.0 & 55.00 & 18.00 & 34.8073 & -25.1055 \\
\hline 4 & 0.05 & 8 & 0.7 & 15 & 20 & 3.5 & 35.00 & 12.00 & 30.8814 & -21.5836 \\
\hline 5 & 0.05 & 10 & 1.0 & 20 & 30 & 5.0 & 15.00 & 9.00 & 23.5218 & -19.0849 \\
\hline 6 & 0.10 & 3 & 0.3 & 10 & 20 & 5.0 & 40.00 & 62.82 & 32.0412 & -35.9620 \\
\hline 7 & 0.10 & 5 & 0.5 & 15 & 30 & 0.5 & 42.57 & 54.00 & 32.5821 & -34.6479 \\
\hline 8 & 0.10 & 7 & 0.7 & 20 & 1 & 1.0 & 57.00 & 34.00 & 35.1175 & -30.6296 \\
\hline 9 & 0.10 & 8 & 1.0 & 1 & 5 & 2.0 & 24.50 & 20.00 & 27.7833 & -26.0206 \\
\hline 10 & 0.10 & 10 & 0.1 & 5 & 10 & 3.5 & 73.00 & 5.00 & 37.2665 & -13.9794 \\
\hline 11 & 0.15 & 3 & 0.5 & 20 & 5 & 3.5 & 50.00 & 60.00 & 33.9794 & -35.5630 \\
\hline 12 & 0.15 & 5 & 0.7 & 1 & 10 & 5.0 & 76.00 & 72.00 & 37.6163 & -37.1466 \\
\hline 13 & 0.15 & 7 & 1.0 & 5 & 20 & 0.5 & 65.00 & 56.00 & 36.2583 & -34.9638 \\
\hline 14 & 0.15 & 8 & 0.1 & 10 & 30 & 1.0 & 86.00 & 20.00 & 38.6900 & -26.0206 \\
\hline 15 & 0.15 & 10 & 0.3 & 15 & 1 & 2.0 & 94.42 & 14.50 & 39.5013 & -23.2274 \\
\hline 16 & 0.20 & 3 & 0.7 & 5 & 30 & 2.0 & 80.00 & 50.00 & 38.0618 & -33.9794 \\
\hline 17 & 0.20 & 5 & 1.0 & 10 & 1 & 3.5 & 96.67 & 40.00 & 39.7058 & -32.0412 \\
\hline 18 & 0.20 & 7 & 0.1 & 15 & 5 & 5.0 & 89.00 & 37.00 & 38.9878 & -31.3640 \\
\hline 19 & 0.20 & 8 & 0.3 & 20 & 10 & 0.5 & 91.00 & 30.00 & 39.1808 & -29.5424 \\
\hline 20 & 0.20 & 10 & 0.5 & 1 & 20 & 1.0 & 86.00 & 7.00 & 38.6900 & -16.9020 \\
\hline 21 & 0.25 & 3 & 1.0 & 15 & 10 & 1.0 & 70.00 & 50.00 & 36.9020 & -33.9794 \\
\hline 22 & 0.25 & 5 & 0.1 & 20 & 20 & 2.0 & 58.00 & 45.00 & 35.2686 & -33.0643 \\
\hline 23 & 0.25 & 7 & 0.3 & 1 & 30 & 3.5 & 92.00 & 37.00 & 39.2758 & -31.3640 \\
\hline 24 & 0.25 & 8 & 0.5 & 5 & 1 & 5.0 & 90.00 & 28.00 & 39.0849 & -28.9432 \\
\hline 25 & 0.25 & 10 & 0.7 & 10 & 5 & 0.5 & 85.00 & 4.00 & 38.5884 & -12.0412 \\
\hline
\end{tabular}

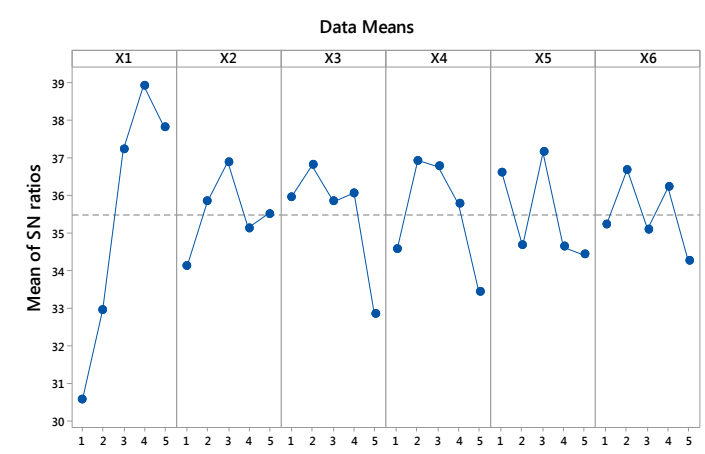

Signal-to-noise: Larger is better

Fig. 1. Main effects plot for $\mathrm{S} / \mathrm{N}$ ratios for $\mathrm{Pb}$ extraction (dashed line indicates mean value)

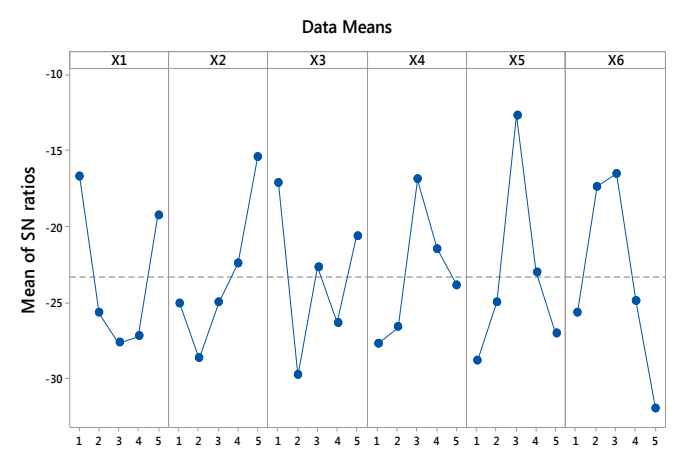

Signal-to-noise: Smaller is better

Fig. 2. Main effects plot for $\mathrm{S} / \mathrm{N}$ ratios for emulsion breaking (dashed line indicates mean value)

ratio and feed phase $\mathrm{pH}$. The interaction between agitation time-feed phase $\mathrm{pH}$, TOPO - Span 80 concentration and Span 80 - internal phase concentration affect to a reasonable degree the emulsion breaking. process variables and the interaction effect on, the mos important phenomenon of ELM, emulsion breaking. From Pareto chart (Figure 4), the great role of Span 80 concentration is seemed followed by the interactive effects of feed/emulsion 


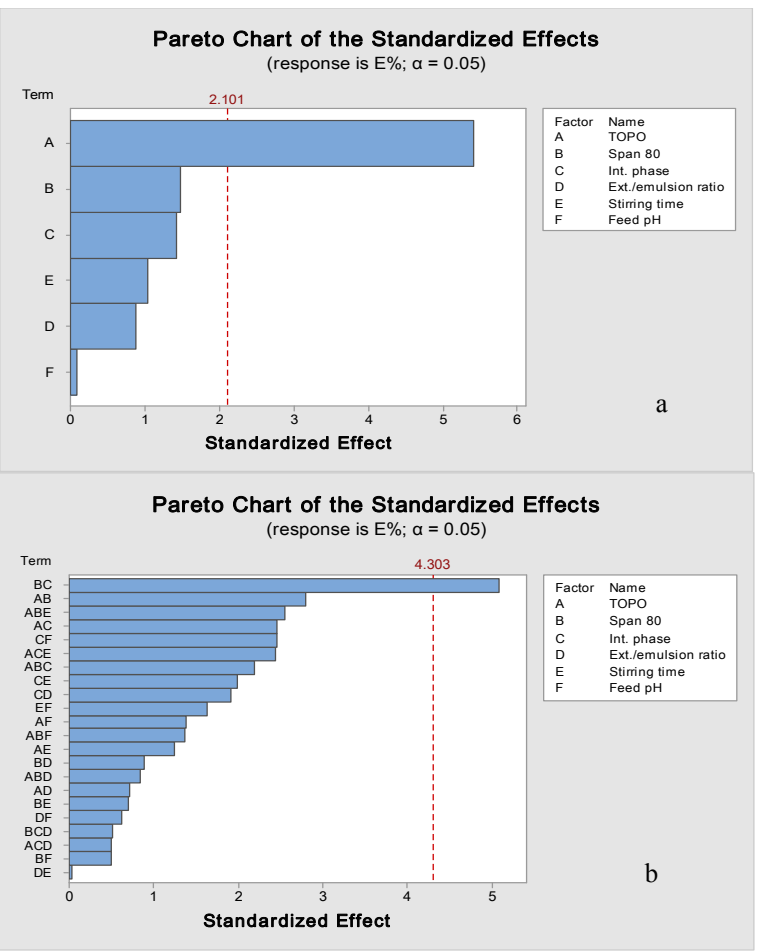

Fig. 3. Pareto chart of a. independent parameters, b. interaction effects of ELM parameters on extraction of lead.

TABLE II. RESPONSE TABLE FOR SIGNAL / NOISE RATIOS OF LEAD EXTRACTION EFFICIENCY (E\%) (LARGER IS BETTER)

\begin{tabular}{|c|c|c|c|c|c|c|}
\hline 苞 & $\begin{array}{l}\sum \\
0 \\
0 \\
0\end{array}$ & 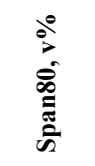 & $\begin{array}{l}\Sigma \\
\dot{\Xi} \\
\tilde{\Xi} \\
\bar{\Xi} \\
\dot{\Xi}\end{array}$ & 离 & 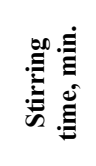 & 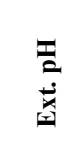 \\
\hline 1 & 30.55 & 34.11 & 35.95 & 34.58 & 36.59 & 35.23 \\
\hline 2 & 32.96 & 35.83 & $36.80^{*}$ & $36.93^{*}$ & 34.66 & $36.68^{*}$ \\
\hline 3 & 37.21 & $36.89^{*}$ & 35.83 & 36.77 & $37.15^{*}$ & 35.08 \\
\hline 4 & $38.93 *$ & 35.12 & 36.05 & 35.77 & 34.63 & 36.22 \\
\hline 5 & 37.82 & 35.51 & 32.83 & 33.41 & 34.43 & 34.25 \\
\hline $\begin{array}{l}\text { Delta } \\
\text { S/N }\end{array}$ & 8.38 & 2.78 & 3.96 & 3.52 & 2.73 & 2.43 \\
\hline Rank & 1 & 4 & 2 & 3 & 5 & 6 \\
\hline DF & 4 & 4 & 4 & 4 & 4 & 4 \\
\hline AdjMS & 63.815 & 5.1571 & 11.752 & 11.14 & 8.1739 & 4.637 \\
\hline SeqSS & 255.26 & 20.628 & 47.011 & 44.59 & 32.696 & 18.55 \\
\hline $\begin{array}{c}\text { Contrib. } \\
, \%\end{array}$ & 60.96 & 4.93 & 11.22 & 10.65 & 7.8 & 4.43 \\
\hline
\end{tabular}

\section{Optimization}

In emulsion liquid membrane process, two responses (Lead extraction, E \% and emulsion breaking, B \%) are existing and they are influenced by ELM process factors. It is necessary to get high values of the $\mathrm{E} \%$ response and low values of the $\mathrm{B} \%$ to provide well ELM performance. More responses influenced by more than one factors was predicted by the Desirability Approach [19]. Considering the ELM process, the extraction yield, E \% is to be maximized to $100 \%$ and breaking, $\mathrm{B} \%$ is to be reduced with the aim of $1 \%$. The optimization was achieved with Minitab Response Optimizer and the optimal factors were found to be TOPO concentration of $0.1498 \mathrm{M}$, Span 80 concentration of $3.007 \mathrm{v} \%$, Internal phase concentration of $0.183 \mathrm{M}, \mathrm{Feed} / \mathrm{emulsion}$ volume ratio of 1.407 , agitation time of 30 minutes, and feed $\mathrm{pH}$ of 5 (Figure 5). As shown in Figure 5 , the predictable extraction, $\mathrm{E} \%$ is $99 \%$ with an individual desirability of 1.0 . The emulsion breaking, $\mathrm{B} \%$ is expected as $1 \%$ with an individual desirability of 1.0 . The composite desirability is estimated to be 1.0 and can be considered as reasonable for the response optimization.

TABLE III. RESPONSE TABLE FOR SIGNAL / NOISE RATIOS OF B\% (SMALLER IS BETTER)

\begin{tabular}{|c|c|c|c|c|c|c|}
\hline ల్త & $\begin{array}{l}\sum \\
0 \\
0 \\
0\end{array}$ & 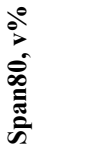 & 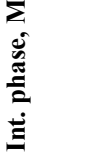 & 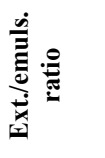 & 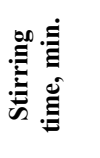 & 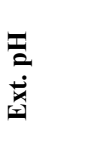 \\
\hline 1 & $-24.72 *$ & -33.81 & $-26.79 *$ & -28.20 & -28.88 & -28.15 \\
\hline 2 & -28.25 & -33.04 & -29.68 & -28.03 & $-26.66^{*}$ & -27.17 \\
\hline 3 & -31.38 & -30.69 & -28.23 & $-26.23 *$ & -27.95 & -28.28 \\
\hline 4 & -28.77 & -26.42 & -27.08 & -28.96 & -28.50 & $-26.91 *$ \\
\hline 5 & -27.88 & $-17.05^{*}$ & -29.22 & -29.58 & -29.02 & -30.50 \\
\hline Delta & 6.66 & 16.76 & 2.88 & 3.34 & 2.36 & 3.59 \\
\hline Rank & 2 & 1 & 5 & 4 & 6 & 3 \\
\hline $\mathrm{DF}$ & 4 & 4 & 4 & 4 & 4 & 4 \\
\hline $\begin{array}{l}\text { Adj } \\
\text { MS }\end{array}$ & 28.317 & 235.71 & 8.081 & 7.958 & 4.572 & 10.053 \\
\hline $\begin{array}{l}\text { Seq } \\
\text { SS }\end{array}$ & 113.27 & 942.86 & 32.32 & 31.83 & 18.29 & 40.21 \\
\hline $\begin{array}{l}\text { Contr } \\
\text { ib., } \%\end{array}$ & 9.6 & 80 & 2.74 & 2.7 & 1.55 & 3.41 \\
\hline
\end{tabular}

\section{CONCLUSIONS}

The optimization for the extraction $\%$ and emulsion breaking of the emulsion liquid membrane process with variations of the process parameters is necessary in order to get high extraction $\%$ and minimum emulsion breaking. In this study, the process parameters TOPO, Span 80, internal phase concentrations, feed/emulsion ratio, agitation time, and feed phase $\mathrm{pH}$ have been optimized via Taguchi method. Some results get up from this study are shortened as follows:

- The effect of emulsion liquid membrane on the $\mathrm{Pb}$ extraction and emulsion breaking were evaluated with help of Taguchi method. TOPO concentration was a dominant factor for extraction efficiency whereas the Span 80 concentration was a dominant factor for emulsion breaking. Optimal emulsion liquid membrane conditions to maximize the extraction efficiency and minimize breaking were determined.

- The linear and quadratic TOPO and Span80 concentrations were more significant founded by the ANOVA and Pareto chart analysis and the linear and quadratic feed phase $\mathrm{pH}$ terms were insignificant.

- As a result of the optimization performed by Response optimizer, for the maximum extraction \% and minimum emulsion breaking, TOPO concentration of $0.1498 \mathrm{M}$, Span 
80 concentration of $3.007 \mathrm{v} \%$, internal phase concentration of $0.183 \mathrm{M}$, Feed/emulsion volume ratio of 1.407 , agitation time of 30 minutes, and feed $\mathrm{pH}$ of 5 are determined as the optimum parameters.

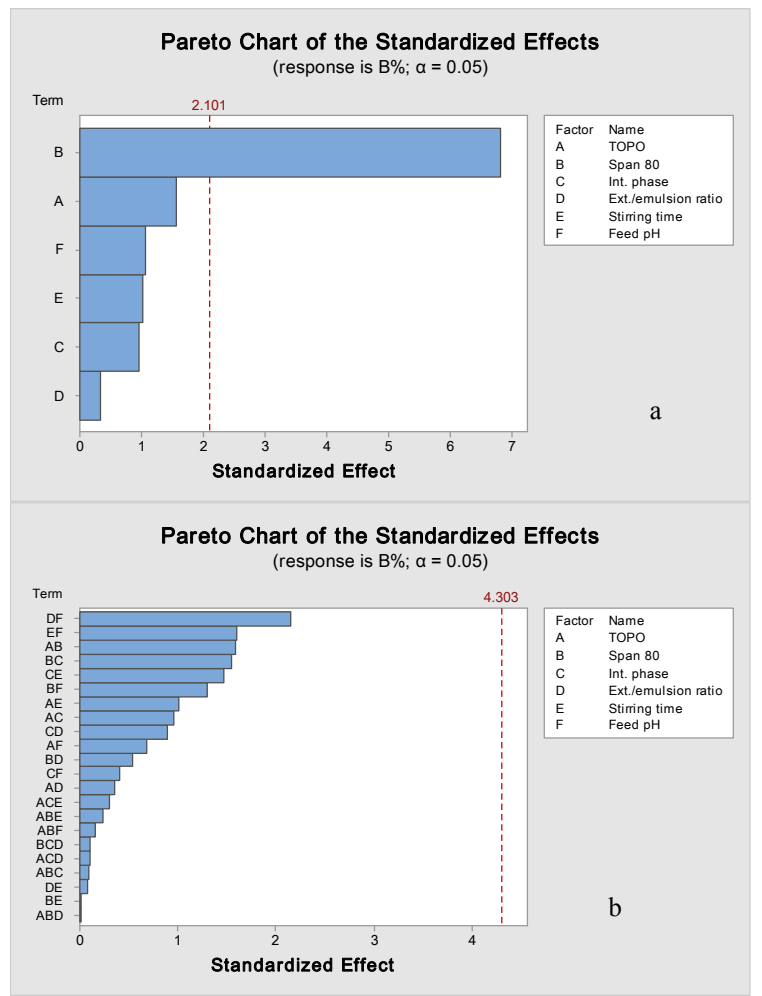

Fig. 4. Pareto chart of a. independent parameters, b. interaction effects of ELM parameters on emulsion breaking.

\begin{tabular}{|c|c|c|c|c|c|c|}
\hline Optimal & ТОРО & Span 80 & $\begin{array}{l}\text { Int. } \\
\text { phase }\end{array}$ & $\begin{array}{l}\text { Feed/e } \\
\text { mul. } \\
\text { ratio } \\
\end{array}$ & $\begin{array}{c}\text { Stirring } \\
\text { time }\end{array}$ & Feed $p H$ \\
\hline $\begin{array}{ccc}\text { Optimal } & \text { Hi } \\
\text { D } & \text { Cur } \\
1.0000 & \text { Lo } \\
\end{array}$ & $\begin{array}{c}0.250 \\
{[0.1498]} \\
0.050\end{array}$ & $\begin{array}{c}10.0 \\
{[3.0070]} \\
3.0\end{array}$ & $\begin{array}{c}1.0 \\
{[0.1830]} \\
0.10\end{array}$ & $\begin{array}{c}20.0 \\
{[1.4071]} \\
1.0 \\
\end{array}$ & $\begin{array}{c}30.0 \\
{[30.0]} \\
1.0\end{array}$ & $\begin{array}{l}5.0 \\
{[5.0]} \\
0.50\end{array}$ \\
\hline $\begin{array}{c}\text { E\% } \\
\text { Targ: } 99.0\end{array}$ & & & & & & \\
\hline $\begin{array}{l}y=99.0 \\
d=1.0000\end{array}$ & & & & & & \\
\hline $\begin{array}{c}\text { B\% } \\
\text { Targ: } 1.0\end{array}$ & & & & & & \\
\hline $\begin{array}{l}y=1.00000 \\
d=1.000\end{array}$ & & & & & & \\
\hline
\end{tabular}

Fig. 5. Response optimizer of Emulsion liquid membrane extraction of lead

\section{ACKNOWLEDGMENT}

The authors wish to acknowledge the approval and the support of this research study by the Deanship of Scientific Research grant No. 4/1/1436/5, Northern Border University, Arar, KSA.

\section{REFERENCES}

[1] A. B. Lende, M. K. Dinker, V. K. Bhosale, S. P. Kample, P. D. Meshram, P. S. Kulkarni, "Emulsion ionic liquid membranes (EILMs) for removal of $\mathrm{Pb}$ (II) from aqueous solutions", RSC Advances, Vol. 4, No. 94, pp. 52316-52323, 2014

[2] J. Lv, H. Yang, Z. Jin, Z. Ma, Y. Song, "Feasibility of lead extraction from waste Cathode-Ray-Tubes (CRT) funnel glass through a lead smelting process", Waste Management, Vol. 57, pp. 198-206, 2016

[3] S. Tokalioglu, E. Yavuz, H. Sahan, S. G. Colak, K. Ocakoglu, M. Kacer, S. Patat, "Ionic liquid coated carbon nanospheres as a new adsorbent for fast solid phase extraction of trace copper and lead from sea water, wastewater, street dust and spice samples", Talanta, Vol. 159, pp. 222230, 2016

[4] P. E. Hande, S. Kamble, A. B. Samui, P. S. Kulkarni, "Chitosan-Based Lead Ion-Imprinted Interpenetrating Polymer Network by Simultaneous Polymerization for Selective Extraction of Lead(II)", Industrial \& Engineering Chemistry Research, Vol. 55, No. 12, pp. 3668-3678, 2016

[5] R. Rahnama, R. Ghadiri, "Separation and preconcentration of trace amounts of lead from water samples using solvent-assisted dispersive solid phase extraction", Journal of the Brazilian Chemical Society, Vol. 26, No. 8, pp. 1642-1647, 2015

[6] L. Pei, L. Wang, "Transport behavior of divalent lead ions through disphase supplying supported liquid membrane with PC-88A as mobile carrier", International Journal of Chemical Reactor Engineering, Vol. 10 , No. 1, pp. 11-24, 2012

[7] O. Arous, H. Kerdjoudj, "Cadmium (II) and lead (II) extraction and transport in supported liquid membrane using TOPO and D2EHPA as mobile carriers", Fresenius Environmental Bulletin, Vol. 18, No. 11, pp. 2130-2132, 2009

[8] S. Björkegren, R. F. Karimi, A. Martinelli, N. S. Jayakumar, M. A. Hashim, "A new emulsion liquid membrane based on a palm oil for the extraction of heavy metals", Membranes, Vol. 5, No. 2, pp. 168-179, 2015

[9] P. C. Mishra, M. Islam, R. K. Patel, "Removal of Lead (II) by Chitosan from Aqueous Medium”, Separation Science and Technology, Vol. 48, No. 8, pp. 1234-1242, 2013

[10] E. A. Fouad, "Zinc and copper separation through an emulsion liquid membrane containing di-(2-ethylhexyl) phosphoric acid as a carrier", Chemical Engineering and Technology, Vol. 31, No. 3, pp. 370-376, 2008

[11] E. A. Fouad, H.-J. Bart, "Emulsion liquid membrane extraction of zinc by a hollow-fiber contactor", Journal of Membrane Science, Vol. 307, No. 2, pp. 156-168, 2008

[12] I. Abou-Nemeh, A. P. Peteghem, "Kinetic study of the emulsion breakage during metals extraction by liquid surfactant membranes (LSM) from simulated and industrial effluents", Journal of Membrane Science, Vol. 70, No. 1, pp. 65-73, 1992.

[13] K. Ranjit, Design of experiments using the Taguchi approach: 16 steps to product and process improvement, Wiley, USA, 2001

[14] M. Rajasimman, R. Sangeetha, P. Karthik, "Statistical optimization of process parameters for the extraction of chromium (VI) from pharmaceutical wastewater by emulsion liquid membrane", Chemical Engineering Journal, Vol. 150, No. 2-3, pp. 275-279, 2009.

[15] N. Benyahia, N. Belkhouche. J. A. Jonsson, “A comparative study of experimental optimization and response surface methodology of Bi (III) extraction by emulsion organophosphorus liquid membrane", Journal of Environmental Chemical Engineering, Vol. 2, No. 3, pp. 1756-1766, 2014

[16] R. Mohammadi, M. A. Mohammadifar, A. M. Mortazavian, M. Rouhi, J. B. Ghasemi, Z. Delshadian, "Extraction optimization of pepsin-soluble collagen from eggshell membrane by response surface methodology (RSM)", Food Chemistry, Vol. 190, pp. $186-193,2016$

[17] F. A. de Bok, C. M. Plugge, A. J. Stams, "Interspecies electron transfer in methanogenic propionate degrading consortia", Water Research, Vol. 38, No. 6, pp. 1368-1375, 2004

[18] H. Y. Yen, "Taguchi optimization for Cd(II) removal from aqueous solutions using oyster shell powders", Desalination and Water Treatment, Vol. 57, No. 43, pp. 20430-20438, 2016

[19] O. Unal, "Optimization of shot peening parameters by response surface methodology", Surface and Coatings Technology, Vol. 305, pp. 99109,2016 